\title{
ENSINO DE ARTE NA ESCOLA: A FORMAÇÃO CONTINUADA DE PROFESSORES EM ARTE DIGITAL ${ }^{1}$
}

\author{
ART TEACHING IN SCHOOLS: TEACHERS \\ CONTINUING EDUCATION IN DIGITAL ARTS
}

\author{
Ana Luiza Ruschel Nunes ${ }^{2}$ \\ Simone Woytecken Carvalho ${ }^{3}$ \\ Thaisa Justus ${ }^{4}$
}

\begin{abstract}
RESUMO
Nesta era em que os estudantes criam páginas na web, animações, gráficos, vídeos, é visível a força da Arte Digital convertendo-se em um novo meio de linguagem. Com isso é necessária uma preparação melhor dos professores para que se utilizem da tecnologia de modo competente e que posam utilizá-la como mais um meio de expressão através das Artes Visuais. É um campo que se encontra largamente por explorar, pois as novas tecnologias digitais podem ampliar as possibilidades do ambiente escolar não só em relação ao uso e exploração desses recursos, como também, para os modos de desenvolvimento da capacidade de pensar, criar e participar de uma sociedade que está em construção. Sensibilizar os professores atuantes e iniciá-los nas novas tecnologias é um ponto fundamental de integração nos atuais processos de ensino, proporcionando tempo e espaço para conhecer, metamorfosear e poetizar a arte numa interação com a educação, tendo em vista analisar na formação continuada o embotamento da criatividade, as anestesias na formação dos professores em relação à prática a produção e a construção criativa artística que infelizmente ainda permanecem na repetição de um fazer artístico estereotipado e vinculado apenas na arte moderna. Assim a arte e tecnologia na contemporaneidade, não colocam em segunda categoria a sensibilidade, e sim desenvolve a capacidade subjetiva e sensível humana, entretanto é preciso que artistas, arte-educadores, e alunos passem por um processo criativo, poético autoral e coletivo para que possam vivenciar e sentir o processo convencional de criação artística e o processo criativo digital contemporâneo em arte, para compreender que a arte digital e sensibilidade e estética andam juntas produzindo emoções de caráter estético
\end{abstract}

Palavras-chave: Formação continuada. Arte digital. Artes visuais. Tecnologia.

\footnotetext{
${ }^{1}$ Este artigo é resultado de projeto da linha de pesquisa Artes Visuais, Educação e Cultura vinculada ao Grupo de Estudos e Pesquisa do GEPAVEC-CNPq/ UEPG/PR

${ }^{2}$ Professora Doutora do Programa de Pós Graduação em Educação.M/D-UEPG/PR, e do Departamento de Artes da Universidade Estadual de Ponta GrossaPR. Coordenadora do GEPAVEC-PROPESP/UEPG/CNPq. Email:analuizaruschel@gmail.com

3 Acadêmica do Curso de Licenciatura de Artes Visuais- UEPG/PR, Bolsista de Iniciação Científica -CNPq-UEPG/2009-atual. Membro do GEPAVEC/ PROPESP/UEPG/CNPQ. E-mail: simonevisuais1@yahoo.com.br

${ }^{4}$ Graduada em Licenciatura em Artes Visuais pela Universidade Estadual de Ponta Grossa. Bolsista PIBIC/CNPQ/UEPG/2008-2009. Membro do GEPAVEC/ PROPESP/UEPG/CNPQ. E-mail: thaisajustus@ig.com.br
} 


\begin{abstract}
In times of web pages, animations, graphics and videos created by students the power of Digital Arts is becoming a new form of language. This demands teachers to be better prepared to use technology efficiently and as another means of expression through visual arts. It is a field that needs to be explored as the new digital technologies can increase the possibilities of the school environment not only in terms of use and exploration of these resources, but also in the development of the capacity to think, create and participate in a society that is under construction. It is necessary to make teachers aware of this and introduce them to the work with new technologies is a key point of integration in current teaching processes, providing time and space to meet, and metamorphose poetize an interaction with the art education in order to analyze the dullness in continuing education creativity, the anesthesia in the training of teachers in relation to practice the art production and creative construction that unfortunately still remain in the repetition of a stereotyped and making art bound only in modern art. Thus in contemporary art and technology, not put in the second category sensitivity, but develops the ability subjective and sensitive man, but it is necessary that artists, art educators, and students go through a creative, poetic and copyright collective for can experience and feel the conventional process of artistic creation and the creative process in contemporary digital art, to understand that digital art and aesthetic sensitivity and emotions go together producing aesthetic.
\end{abstract}

Keywords: Continuing education. Digital arts. Visual arts. Technology.

\section{Introdução}

Nesta era em que os estudantes criam páginas na web, animações, gráficos, vídeos, é visível a força da Arte Digital convertendo-se em um novo meio de linguagem. Com isso é necessária uma preparação melhor dos acadêmicos e professores para que se utilizem da tecnologia de modo competente e que posam utilizá-la como mais um meio de expressão através das Artes Visuais.

É um campo que se encontra largamente para melhor desenvolver a inclusão digital, pois as novas tecnologias podem ampliar as possibilidades do ambiente escolar não só em relação ao uso e exploração desses recursos, como também, para os modos de desenvolvimento da capacidade de pensar, criar e participar de uma sociedade que na atualidade desenvolve relações sociais através das redes sociais, e que na educação escolar a inclusão da tecnologia e mais específicamente a arte digital ainda é tênue no espaço escolar.

Sensibilizar os professores atuantes e iniciálos nas novas tecnologias é um ponto fundamental de integração nos atuais processos de ensino, proporcionando tempo e espaço para conhecer, metamorfosear e poetizar a arte numa interação com a educação, tendo em vista analisar na formação continuada o embotamento da criatividade no processo criativo em artes digital, as anestesias na formação dos professores em relação à prática a produção e a construção criativa artística que infelizmente ainda permanecem muito visível na repetição de um fazer artístico estereotipado e vinculado apenas na arte moderna e reprodutora, ainda que há exceções.

Segundo Ferreira (2008)

Devemos ter presente, ainda, que a arte tecnológica tem como meta sensibilizar por meio do uso de técnicas e processos. O seu maior propósito é produzir emoções de caráter estético, pelo seu conteúdo original. Por isso mesmo acreditamos que o público necessita de um novo olhar sobre as obras de arte elaboradas pelos meios eletrônicos.

Assim a arte e tecnologia na contemporaneidade, não coloca em segunda categoria a sensibilidade, e sim desenvolve a capacidade subjetiva e sensível humana, entretanto é preciso que artistas, arte-educadores, e alunos passem por um processo criativo, poético autoral e coletivo para que 
possam vivenciar e sentir o processo convencional de criação artística e o processo criativo digital contemporâneo em arte, para compreender que a arte digital e sensibilidade e estética andam juntas produzindo emoções de caráter estético

Por outro lado a dimensão poética na educação e arte, ou poiésis, é o foco desta pesquisa sobre a construção expressiva na arte digital, investigando o tempo o espaço de experienciação poética, os desmembramentos metodológicos do processo criativo e o desenvolvimento da educação do sensível na formação continuada de professores de artes visuais, professores das escolas públicas do núcleo regional da cidade de Ponta Grossa/PR.

Partindo da observação e reflexão da realidade de cada um dos participantes, como diz Nunes (2004) tendo o computador como ateliê na produção em arte digital num percurso e repertório pessoal.

Assim a pesquisa segundo Nunes (2009) é alavancadora de novos conhecimentos, pois oportuniza aos docentes e seus alunos um novo percurso colaborativo no ensino das artes visuais e tecnologias digitais, através da reflexão-ação e da reflexão sobre a ação, para com isso vivenciar a construção poética na elaboração artística em interação com a tecnologia a partir da realidade de cada indivíduo e de sua cultura vivida.

Julio Plaza (1998) em seu livro "Processos Criativos com os Meios Eletrônicos: Poéticas Digitais" afirma que a arte se modifica de acordo com a estrutura cultural e econômica de cada sociedade. A cada passo da evolução humana os aparatos técnicos se aprimoram e por isso ocorrem modificações no modo de interagir com a arte. A evolução da forma de se fazer arte passa por três fronteiras quando surgem novas tecnologias: a) pré industrial-com a interação do homem e do objeto através da pintura, desenho, caligrafia, escultura, dança. b) período industrial- através da gravura, fotografia, cinema e artes gráficas, onde a representação era fiel ao real. C) pós industrial- com a chegada da tecnologia digital com informações visuais, sonoras e verbais, todas juntas representavam o mesmo objeto.

Isto remete a pensar o que a escola pensa da arte contemporânea, o que diz a arte contemporânea para os professores que atuam no ensino de Artes Visuais escolar?Da mesma forma a reflexão se insurge a refletir, o que a criança e adolescentes esperam da arte contemporânea escolar, se como enfatiza Cauquelin (2005, p. 11) “Arte contemporânea é a arte do agora, a arte que se manifesta no mesmo momento em que o público a observa. Tão somente se trata de arte moderna se entendermos por moderno o século XX em geral"

E assim,a proposição de trabalhar com a formação continuada nos acena para novas narrativas pedagógicas que tem a arte digital como possibilidade de arte na atualidade via tecnologia como coloca Nunes (2009) como Hiperferramenta e não apenas como ferramenta para o ensino de Artes Visuias na escola.

\section{Formação continuada de professores}

Desenvolver uma pesquisa tendo como temática e foco de investigação a Formação Continuada de Professores de Artes Visuais, e ainda buscar a construção de uma metodologia possível de encontro às novas tecnologias, exige bases teórica e estudos mais aprofundados em relação a estas categorias. Para isso alguns conceitos norteadores fundamentam esta investigação.

\section{Entende-se por Formação Continuada:}

A formação recebida por formandos já profissionalizados e com vida ativa, tendo por base a atualização contínua a mudanças dos conhecimentos, das técnicas e das convicções de trabalho, o melhoramento de suas qualificações profissionais e a sua promoção profissional e social. (NASCIMENTO, 1995 apud MERCADO, 1999, p. 105).

A respeito da formação continuada, Perrenound (2000, p.165) afirma que, "uma formação comum no estabelecimento (quando se convive na mesma escola), faz evoluir o conjunto do grupo, em condições mais próximas do que uns e outros que vivem cotidianamente".

Segundo Garcia:

A formação centrada na escola compreende as estratégias que empregam conjuntamente os formadores e os professores para dirigir programas de formação de maneira que respondam as necessidades definidas da escola e para elevar as normas de ensino e de aprendizagem na classe. Esta concepção se fundamenta no desenvolvimento profissional do professor entendida a escola como o lugar onde surgem e se podem resolver a maior parte dos problemas do ensino. Por isso esta formação se 
realiza prioritariamente no local de trabalho e durante o tempo escolar por envolver mais os professores. (GARCIA, 1996 apud MERCADO, 1999, p.137).

Para tanto, foi importante a formação continuada ser realizada não só em ambiente acadêmico no ensino superior, foi importante a formação continuada em serviço, se apropriando dos espaços dos laboratórios de Informática de escolas em que se deu a formação em arte digital, respondendo as necessidades definidas da escola.

Foi necessário na formação continuada que todos os professores em formação compreendessem e tivesem uma concepção sobre poética digital e nesta direção compreende-se por poética digital a poesia que surge para estabelecer uma interconexão entre poesias visual, sonora, verbal e existente, ou seja, a poesia na possibilidade interdisciplinar. Ainda que muito tem se avançado nas produções artísticas, estas são metáforas e são ficções reveladoras, criadas pelos sentidos, percepção, imaginação, sentimento, pensamento e memória simbólica do ser humano e cultural. Esses sentidos são imprescindíveis para que uma elaboração poética possa ser construída no instante poético, no ato e na potência de ser, como nos pontua Bachelard (1998) A construção poética se origina na percepção que se encontra em conexão direta com o espírito, ou seja, com o sentir, fruir e o saber.

Segundo Bachelard (1998), para construir um instante poético, o poeta destrói a continuidade simples do tempo ligado, para atar nesse instante numerosas simultaneidades. Assim, oriundo dessas simultaneidades dos sentidos, o ser humano poetiza sua relação com o mundo, e o artista e também podemos dizer o artista e professor ao se debruçar sobre seu universo interior e exterior, usa a techné, sua capacidade de operar os meios com sabedoria, com a poiesis, sua capacidade de criação, desvelando verdades presentes na natureza e na vida que ficariam submersas sem sua presentificação.

A sensibilidade do artista e professor traduz-se no seu instante poético, de trabalho criador, onde expressa a felicidade do momento, a alegria de viver e poder libertar aquela verdade interior através do trabalho criado, ele artísta e professor é único na preparação/construção criativa de cada um dos trabalhos, sendo traduzido em uma imagem. Assim a poética surge como reveladora das nossas possíveis verdades subjetivas e objetivas.

Martins, et al. (1998, p.46) afirma, "nessa construção, o artista [e o professor] percebe, relê e repropõe o mundo, a vida e a própria arte, produzindo imagens únicas e insubstituíveis, imagens poéticas".

Cabe assim ao professor possibilitar a cada um de seus alunos o fazer artístico como marca e poética pessoal.

Da obra de arte transpiram completamente a personalidade e a espiritualidade originais do artista, que antes de se manifestarem no assunto e no tema se manifestam no irrepetível e personalíssimo modo de formá-las [...] Conteúdo da obra é a própria pessoa do criador que ao mesmo tempo, se faz forma. (ECO, 1986, p. 17)

Para tanto na presente pesquisa, tudo foi sendo contruído num percurso permanentemente de investigação-ação de forma colaborativa e compartilhada do grupo como professora pesquisadora em arte digital na formação continuada, e bolsistas de iniciação científica - PIBIC/CNPq/UEPG(2008-2009) Thaísa Justus, e bolsista de Iniciação Científica do PIBIC/ CNPq/UEPG(2009 até o momento atual) Simone Woytecken Carvalho, estudar e construir projetos de pesquisa visando a formação de professores em Artes Visuais na produção da arte digital. Assim todo o grupo em colaboração investigou, mapeando todo o levantamento do uso da arte digital nas escolas em relação ao ensino de Artes Visuais, e analisaram posteriormente a partir dos dados, adentraram os espaços cedidos pela gestão da escola e professores. A partir de então desde 2008, o grupo realiza um trabalho criativo com produção em arte digital utilizando a tecnologia digital como uma nova forma de ampliar o campo de possibilidades do ambiente escolar, tendo a dimensão poética do trabalho criador em arte e educação, ou poiésis, como foco desta pesquisa sobre a construção expressiva na arte digital, investigando como diz Bachelard (1998) o tempo, o espaço de experienciação poética, a processualidade do processo criativo autoral e o desenvolvimento da educação do sensível na formação inicial e continuada de professores de Artes Visuais de escolas públicas, pertencentes ao Núcleo Regional de Educação, da cidade de Ponta Grossa/PR.

Assim, a poiésis, considera-se o trabalho criador com uma vontade autoral, constituída no instante 
poético, ou seja, o processo poético, cuja narrativa visual e textual somam-se desvendando a produção, a ação, enfim a práxis em arte através de procedimentos utilizando os saberes e fazeres com os elementos da linguagem visual no espaço virtual, tendo o computador como espaço de ateliê.

\section{Percursos e trilhas do caminhar metodoló- gico investigativo}

A abordagem da pesquisa é qualitativa delineada pela investigação-ação. Este estudo tem como um dos espaços os laboratórios de informática do Departamento de ARTES/UEPG/PR.(Fig.1). Ainda pode- se visualizar os Laboratórios de Informática (Fig. 2 e 3), de escolas estaduais da cidade de Ponta Grossa/PR, envolvidas na pesquisa.

Figura 1 - Laboratório do Departamento de Artes/UEPG Fotografia de Ana Luiza Ruschel Nunes

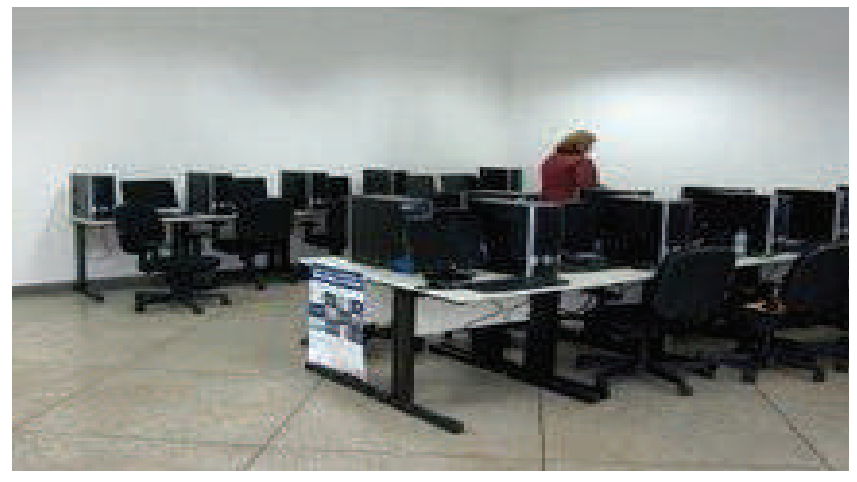

Fonte: Portfólio das pesquisadoras

Figura 2 - Professora de Artes Visuais da escola envolvida Laboratório de Informática na Escola Fotografia de Ana Luiza Ruschel Nunes

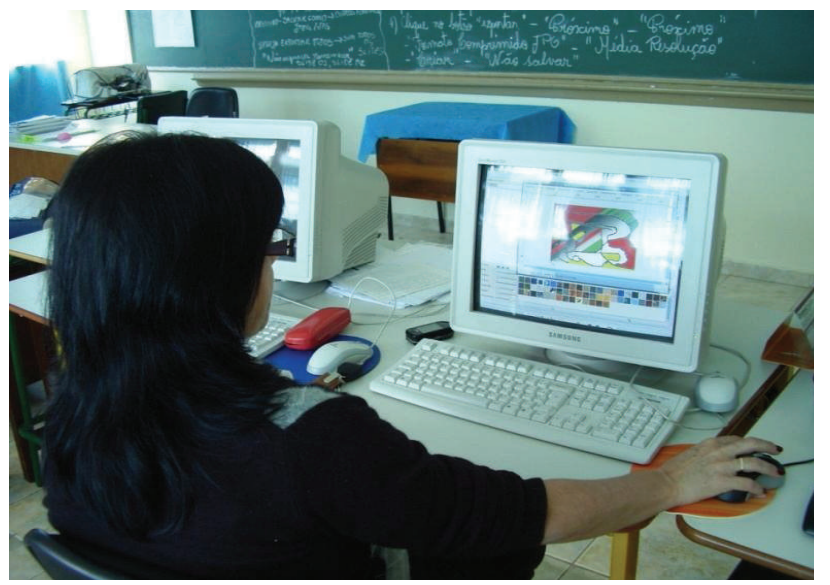

Fonte: Portfólio das pesquisadoras
Figura 3 - Professora e acadêmica bolsista- pesquisadoras em Artes Visuais

Laboratório de Informática da Escola envolvida e Grupo de Trabalho em Rede- GTR Fotografia de Neuci Martins

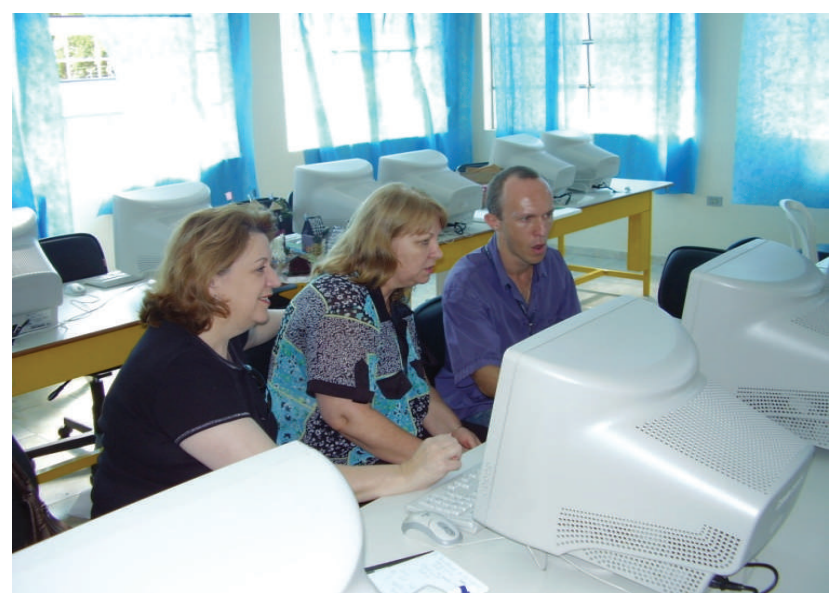

Fonte: Portfólio das pesquisadoras.

Os instrumentos de análise são: observação participante onde pesquisadores e pesquisados estavam envolvidos cotidianamente neste processo, entrevista com grupos focais e também de forma individual com cada participante colaborador da pesquisa,subsidiada pelos fundamentos de Bauer e Gaskell (2002). Também o diário de campo com registro dos pesquisadores do processo como um todo, em especial do desenvolvimento criativo da arte digital e seu percurso produtivo, o portfólio virtual de cada pesquisado e dos pesquisadores do processo, fotografia digital como mais uma ampliação para a criação poética, computadores e software - programas especiais para produção em arte. Sendo assim os envolvidos como pesquisados são professores de Arte das escolas, sendo um total de 34 professores, organizados por grupos em cada uma das escola envolvidas.

Cada professor posterior a formação desenvolveu com seus alunos na escola uma prática educativa possibilitando multiplicar a formação em arte digital no ensino de Artes Visuais se apropriando de outro espaço na escola- a sala do Laboratório de Informática das mesmas, o que possibilitou o desenvolvimento e formação humana, e a acessibilidade e inclusão aos professores e alunos em lidar com as ferramentas e saberes para produzir arte digital num outro modo de produzir, em que a ciência, técnica, 
tecnologia e sociedade são fundantes e presentes na reflexão e ação frente ao mundo da expressão artística na sociedade atual.

Assim a análise qualitativa que, segundo LÜDKE; ANDRÉ (1986, p.11), tem o ambiente natural como sua fonte direta de dados e o pesquisador como seu principal instrumento. O método de pesquisa foi o da pesquisa-ação através de processos compartilhados que para. Kemmis e Metaggart: (1998, p.9)

A investigação-ação é uma forma de indagação introspectiva coletiva empreendida por participantes em situações sociais com objetivo de melhorar a racionalidade e a justiça de suas práticas sociais e educativas, assim como sua compreensão destas práticas e das situações em que estas têm lugar.

Soma-se ainda ao que o autor acima explicita, tomando para os pesquisadores o que Thiollent (1996, p.15) nos diz que a "pesquisa-ação é quando houver realmente uma ação por parte das pessoas implicadas no problema da observação". E é isto o que já empreendemos e estamos empreendendo neste caminhar da pesquisa. Essa se dará em colaboração dos pesquisadores e pesquisados em aprendizado mútuo, e compartilhado num processo de dupla aprendizagem da criação em Arte digital.

\section{A caminhada se faz caminhando: alguns resultados}

Dando continuidade do processo investigativo iniciado pela Professora pesquisadora e acadêmica Thaísa Justus participante do Grupo de Pesquisa em Artes Visuais, Educação e Cultura - CNPq/UEPG, e bolsista de Iniciação Científica com bolsa PIBIC/ CNPq (2008-2009), com resultados mais contundentes na investigação de arte digital na formação inicial (ver fig.4 abaixo produção em Artes Visuais digital)
Figura 4 - Arte Digital, Produção de acadêmica do Curso de Licenciatura em Artes Visuais Laboratório de Informática do Departamento de Artes- UEPG Fotografia de Ana Luiza Ruschel Nunes

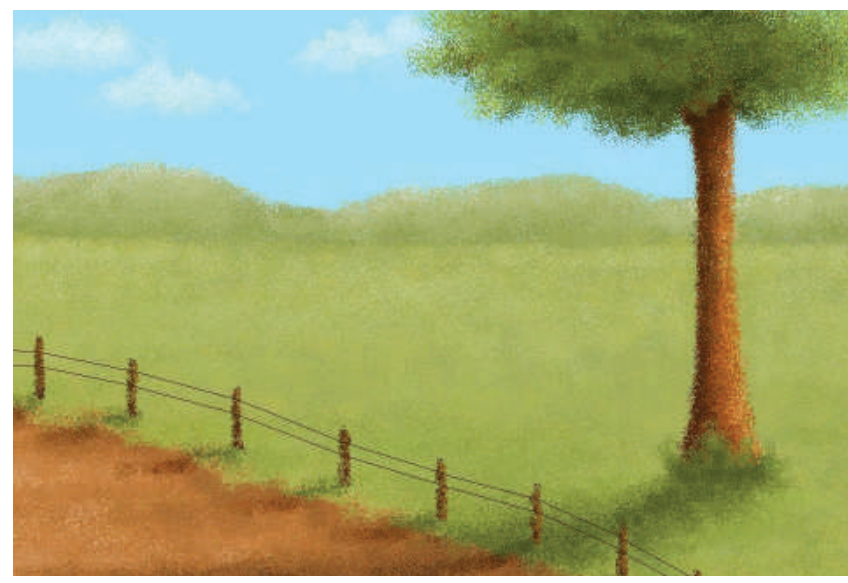

Fonte: Portfólio das pesquisadoras

Decidiu-se no grupo de pesquisa dar melhor desenvolvimento na pesquisa pelo viés da formação continuada de professores de artes, tendo como colaboradores os professores das escolas do Núcleo Regional de Educação de Ponta Grossa/PR, E sendo assim, e estando o processo em fase processual, destacamos que se têm como resultados que, se faz necessário as aprendizagens significativas no ensino de Artes Visuais, na escola. Propiciar uma nova cultura didático-pedagógico frente à inserção das tecnologias digitais no ensino de Artes Visuais, desafia, como diz Nunes, em sua pesquisa realizada em 2004 que ao desenvolver uma investigação sobre arte e tecnologia, mais especificamente sobre o processo poético digital e os novos modos de produção em Artes Visuais, nos faz referência ao computador como ferramenta e hiper-ferramenta dizendo e reafirmando em sua pesquisa no ano de 2009,como explicita,

Com tudo isso, sem dúvida o computador com seus programas gráficos, abre uma nova perspectiva na criação artística, por meios tecnológicos que atingem significativamente o modo das pessoas de produzir, conviver, relacionar-se, transformando consubstancialmente a forma de criar em arte, seja no seu plano de expressão e comunicação através dos elementos formais, em que o conteúdo aí se fundiu em narrativas visuais, exigindo um novo sentido estético e poético, cujas vivências traduzem-se em tempo e espaço que se manifestam 
por uma sociedade [...] frente ao contexto do século XXI. (NUNES, 2009, s/p)

Assim, inserir o ensino de arte numa concepção mais contemporânea, destacando que é possível hoje trabalhar arte digital na escola, de forma positiva, com os programas gráficos possíveis através do computador o tornando primeiro uma ferramenta e posteriormente como hiperferramenta produzindo arte via tecnologia e não apenas tendo o computador como ferramenta, é um desafio na atualidade, diante da formação de professores de Artes Visuais. Propiciar que professores de artes visuais possam conhecer, acessar e produzir poéticas em arte digital tendo uma formação continuada, usando o computador como ateliê de produção. Implantar uma metodologia do ensino da arte na escola pelos professores de Artes Visuais, no processo criativo das poéticas visuais oportunizando aos alunos o acesso e possibilidade de criação de suas poéticas autorais. Construir conhecimento dos saberes disciplinares, neste caso do conhecimento da linguagem visual e tecnologias digitais bem como dos saberes pedagógicos e metodológicos do ensino da arte.

Pode-se inferir pelos resultados dos dados, que o processo de criação autoral encontra barreiras inconscientes e inibidoras para alguns alunos e professores que durante sua trajetória de formação não tiveram oportunidade de vivências e habilidades artísticas criativas digitais, refletindo sobre $\mathrm{o}$ processo expressivo ainda frágil, mas que avançou na criação em Artes Visuais. Foi percebido assim, que os padrões estéticos repetitivos imperavam no fazer artístico dos mesmos. Para a maioria dos participantes a percepção do sensível foi presentificada, no aprofundamento de sua "poiésis", onde emergiram sensações digitais e a satisfação de criação de visualidades com um novo sentido, uma produção em arte até então não experimentada. Num total de cinco professores um possuia até então, experienciAÇÃO em poéticas digitais em arte, e os demais não possuiam conhecimento e experiência prática artística em arte digital, e sendo assim, tiveram dificuldades maiores em seu processo criativo, pois não haviam utilizado e nem sabiam usar os procedimentos metodológicos do software para desenho e produção artística disponibilizado pelo Linux (escola) em que tal programa, sendo o mais simples- o GIMP, está disponível em todos os computadores das escolas do Estado do Paraná.
No início da criação o pensamento dos colaboradores, foi a de que na arte digital tudo era mecânico e sem significado, mas ao construir as poéticas, entenderam que a sensibilidade está presente na criação da arte digital e que somos nós humanos, que humanizamos o computador a serviço de uma humanidade mais humanizada (NUNES, 2009).

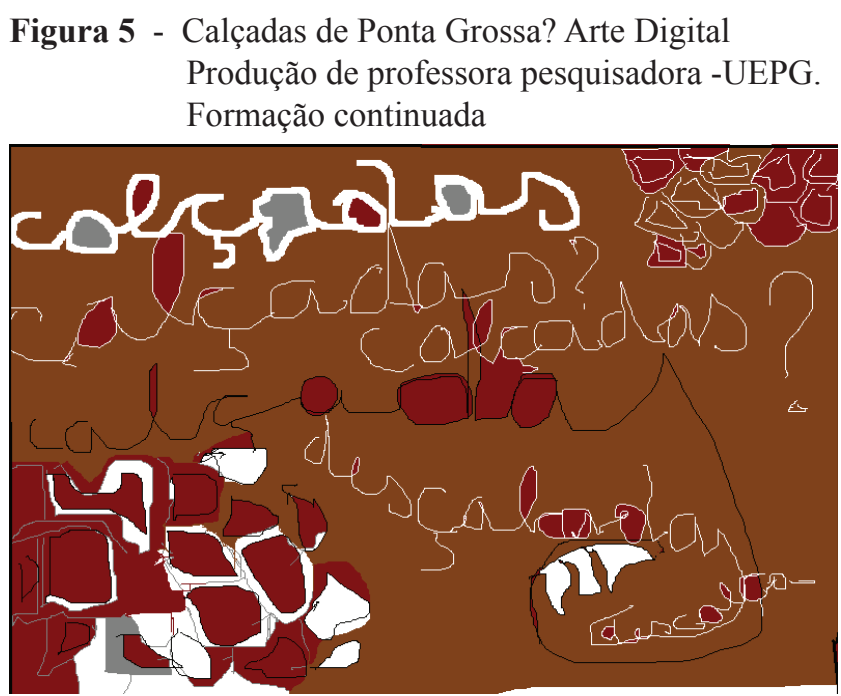

Fonte: Portfólio das pesquisadoras

Figura 6 - Jarras. Arte Digital. Produção de professora de escola. Formação continuada

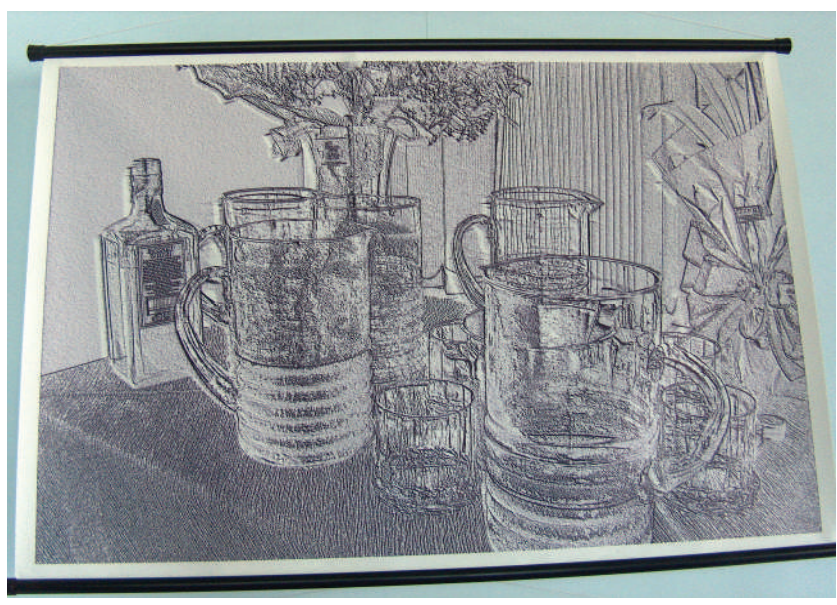

Fonte: Portfólio das pesquisadoras

A experiência com softwares na experienciAÇÃO e criAÇÃO, deu possibilidades interativas com a máquina, transpondo barreiras técnicas, de recurso, de percurso metodológicos com o computador como ferramenta e hiperferramenta na criação da arte digital, e também a possibilidade de conhecer e compreender como trabalhar os recursos 
gráficos e programas, disponíveis no tratamento e expressão criativa de imagens.

Uma das professoras em formação continuada, ao ser indagada sobre qual o seu percurso criativo da poética ao produzir sua obra de arte e qual a importância desse processo em sua vida pessoal e profissional, disse: “... a natureza morta me atrai e buscar maneiras diferentes de representá-la sempre foi um desafio pra mim e a arte digital vem de encontro a essa minha busca, ela possibilita inúmeros recursos para produzir uma obra de arte original" (fala da professora).

Em relação ao manejo dos programas que utilizou, como o GIMP, com possibilidade na escola, e de quais foram suas maiores dificuldades, destacamos a narrativa de uma das professoras "... as dificuldades foram em manusear as ferramentas do Programa, tem que ter mais firmeza no traço. No vaso do Lírio seria o trabalho duplo, pois trata- se de duas produções digitais, primeiro a foto da obra original na escola, da temática para fundir na forma expressiva criada pelo processo digital, trabalhda no Gimp", e o resultado pode ser lido e apreciado por todos como se observa na obra "Jarras" na fig.06, acima. Este processo desafiou a todos os envolvidos, sentindo a necessidade cada vez mais de formação contínua.

Como nos diz Justus (2009 p114)

Que há uma urgente necessidade de um novo olhar sobre o ensino das Artes Visuais com uma didática pedagógica diferenciada visando incorporação das novas disciplinas com abordagens tecnológicas que preparem o professor para o planejamento, implantação e avaliação da utilização do computador como ferramenta de trabalho em sala de aula.

Esta constatação de Justus (2009) é importante porque este novo olhar precisa de enfrentamentos de conhecimento e experienciação na produção em arte digital, pois o contexto sócio educativo esta a exigir novas formas de ensino e aprendizagem tendo em vista a práxis da arte digital, e na ampliação e conhecimento da complexidade da tecnologia e arte, na contemporaneidade.

\section{Considerações}

Conclui-se que as tecnologias digitais em Artes Visuais ainda não estavam presentes na escola envolvida. A pesquisa mostrou que o computador era usado, mas a produção digital era desconhecida, e, portanto percebeu- se que o ensino da arte estava sob os fundamentos e produção que podemos dizer convencional no processo de criação e a arte e sua criação digital ainda não tinha adentrado nas escolas investigadas, e assim não existia a arte digital no ensino de Artes Visuais, na escola. Por outro lado também não existia até o ano de 2008, o ensino da produção em arte digital, só possível quando se inseriu a pesquisa em poéticas digitais, na disciplina de Metodologia da Pesquisa em Arte II, ministrada pela professora Ana Luiza Ruschel Nunes, do Curso de Licenciatura em Artes Visuais da UEPG/ PR, cujo trabalho de pesquisa vem desenvolvendo, desde 2004. No Curso já referido acima, a produção em Arte Digital se originou na formação inicial e se expandiu para a formação continuada, que já soma 4 (quatro) anos de investigação em poética digital.

Contudo, pode-se afirmar que a produção poética digital é possível a partir de um processo de criação, transformando as ferramentas e o modo de produzir arte na contemporaneidade, que nos leva a refletir sobre a percepção da complexidade do uso do computador como instrumental de comunicação e interação humana, nos oferecendo ainda a possibilidade de conhecimentos na área de Artes Visuais e tecnologia,aliando Ciência, técnica e tecnologia na criação poética digital, compreendendo que sem o humano, a máquina por si só, não produz arte, e portanto só o humano pode engendrar a criação em arte digital. Atualmente arte, ciência, técnica e tecnologia se interconectam numa relação inter e multidisciplinar, em que cada um desses fenômenos de conhecimento tem sua parcela na compreensão do todo dos fenômenos estudados em relação as Artes Visuais.

Sendo assim, a processualidade dessas pesquisas, ampliam o percurso e processo dos investigadores, atualmente desenvolvida pela professora pesquisadora e com projeto de iniciação científica do PIBIC/UEPG da acadêmica Simone Woytecken Carvalho, com alunos das escolas da 
Educação Básica e com os Funcionários (Prófuncionários) das escolas da cidade de Ponta Grossa/ PR, e cuja investigação se amplia envolvendo outros colaboradores e outros contextos na região de Ponta Grossa/PR, em que o ensino, a pesquisa e extensão, indissociadas se unem a comunidade educacional na formação inicial e continuada de professores de Artes Visuais.

\section{Referências}

BACHELARD, Gaston. A poética do devaneio. São Paulo: Martins Fontes, 1998.

BAUER Martin W.; GASKELL George. Pesquisa qualitativa com texto, imagem e som. Petrópolis, RG: Vozes, 2002.

ECO, UMBERTO. Os limites da interpretação. São Paulo: perspectiva, 2000.

FERREIRA, Aurora. Arte, tecnologia e educação: as relações com a criatividade. São Paulo: Annablume, 2008.

JUSTUS, Thaisa. Poéticas em arte digital: um olhar contemporâneo na formação de professores. 2009,134p. Trabalho de Conclusão de Graduação- TCC (Graduação Licenciatura em Artes Visuais) - Universidade Estadual de Ponta Grossa, Ponta Grossa, 2009.

LÜDKE, Menga. A avaliação do aluno e a questão curricular. In: CONGRESSO BRASILEIRO DE EDUCAÇÃO, 5. Brasília, 1988.

MERCADO, Luís P. L. Formação continuada de professores e novas tecnologias. Maceió: Ed-UFAL, 1999.

MARTINS, Mirian. C. F. D. Didática do ensino da arte: a língua do mundo: poetizar, fruir e conhecer arte. São Paulo. FTD, 1998.

NUNES, Ana Luiza Ruschel. Arte digital na formação continuada de professores de Artes Visuais: o computador como ferramenta e hiperferramenta. In: ENCONTRO NACIONAL DOS PESQUISADORES EM ARTES PLÁSTICAS, 18. Salvador /Bahia, 2009. Anais... Cd- Rom, p.3056-3070.

NUNES, Ana Luiza Ruschel; JUSTUS, Thaisa. Formação inicial e continuada de professores de Artes Visuais e o percurso criativo com poéticas em arte digital. Relatório de Pesquisa- Linha de pesquisa Artes Visuais, Educação e Cultura-PROPESP, Universidade Estadual de Ponta Grossa, Ponta Grossa, 2009.

PERRENOUD, Philippe et al. Formando professores profissionais: quais estratégias?

Quais competências? Porto Alegre: Artmed, 2001.

PLAZA, Julio; TAVARES, Monica. Processos criativos com os meios eletrônicos: poéticas digitais. São Paulo: HUCITEC, 1998.

THIOLLENT, Michel. Metodologia da pesquisa-ação. São Paulo: Cortez, 2000. 